\title{
EFFECTS OF DENSITY-DEPENDENT AND STOCHASTIC PROCESSES ON THE REGULATION OF COD POPULATIONS
}

\author{
Jean-Marc Fromentin, ${ }^{1,4}$ Ransom A. Myers, ${ }^{2}$ Ottar N. Bjørnstad ${ }^{3,4}$ Nils Chr. Stenseth, ${ }^{4,5,7}$ \\ JAKOB GJøSÆTER,,$^{5}$ AND Hartvig Christie ${ }^{6}$ \\ ${ }^{1}$ Institut Français de Recherche pour l'Exploitation de la MER (IFREMER), Département des Resources Halieutiques, \\ 1 rue Jean Vilar, BP 171, 34203 Sète Cedex, France \\ ${ }^{2}$ Dalhousie University, Department of Biology, Halifax, Nova Scotia, Canada B3H 4JI \\ ${ }^{3}$ National Center for Ecological Analysis Synthesis (NCEAS), 735 State Street, Suite 300, \\ Santa Barbara, California 93101 USA \\ ${ }^{4}$ Division of Zoology, Department of Biology, University of Oslo, P.O. Box 1050 Blindern, N-0316 Oslo 3, Norway \\ ${ }^{5}$ Institute of Marine Research, Flødevigen Marine Research Station, N-4817 His, Norway \\ ${ }^{6}$ Norwegian Institute for Nature Research, P.O. Box 736, Sentrum, N-0105 Oslo, Norway
}

\begin{abstract}
We analyzed 136 time series (covering from 44 to $73 \mathrm{yr}$ ) of juvenile cod to estimate the level of direct and delayed density-dependent mortality (DDM) of 11 populations from the Norwegian Skagerrak coast. The parameters were estimated using a modeling approach that explicitly incorporates observation errors, so that we could quantify the density-independent (stochastic) variation in the survival of juvenile cod. Moderate to strong levels of DDM (direct or delayed) were estimated in eight of the 11 populations. Variability in the 0-group (corrected for observation errors) appeared to be large for most of the populations. Substantial stochastic variability in postsettlement survival was also detected in some areas, indicating that stochastic factors are not only important for egg and larval stages, as stated by the match-mismatch hypothesis, but also for juveniles. We show that the variability in these coastal populations is not only regulated as a function of the strength of DDM processes, but also as an interaction between DDM processes and stochastic factors. We finally postulate that local and regional differences in the strengths of the density-dependent and stochastic processes are related to differences in the quantity and quality of the bottom flora coverage, which govern both food availability and shelter for juveniles.
\end{abstract}

Key words: bottom flora coverage; cod population dynamics; fjord; Gadus morhua; mortality, delayed density-dependent; mortality, direct density-dependent; observation errors; stochastic survival, juvenile.

\section{INTRODUCTION}

Since Johan Hjort's pioneering work (1914), studies on temperate marine fish populations have emphasized stochastic variation within early stages (e.g., May 1974, Cushing 1995). However, evidence of high levels of predation and/or cannibalism acting on the 0-group juvenile cod (Folkvord and Ottera 1993, Gotceitas et al. 1995, Pepin and Shears 1995, Tupper and Boutilier $1995 a, b$, Borg et al. 1997, Levin et al. 1997), as well as the presence of density-dependent mortality (DDM) within the juvenile stages (Myers and Cadigan 1993a, Bjørnstad et al. 1999a), also point to variation in survival of the juvenile stages as being important.

From a theoretical point of view, interactions within and between cohorts may be expected to modify the variability across the different age classes (e.g., Hixon and Carr 1997). When these interactions result in DDM within early stages, the population may be regulated, so that the level of variability becomes relatively lower

${ }^{7}$ Corresponding author: E-mail: n.c.stenseth@bio.uio.no for adults than juveniles (Myers and Cadigan 1993a). In this article, we use regulation in the strict sense of reducing the variability.

Quantifying the relative importance of the densitydependent and the density-independent components of mortality in free-ranging populations has been generally hampered by the lack of long time series (Hassell et al. 1989) and the presence of observation errors (Lebreton 1989, Myers and Cadigan 1993a, Bjørnstad et al. 1999a). Here, we overcome the first of these problems by quantifying DDM within juvenile stages through the analysis of 136 time series of 44-73 yr from 11 cod populations, sampled along the Norwegian Skagerrak coast (Gjøsæter 1990, Johannessen and Sollie 1994, Fromentin et al. 1997, 1998). We used a modeling approach that explicitly models observation errors to overcome the second problem. The model (Myers and Cadigan 1993a, b), which is similar to the key factor analysis (e.g., Begon et al. 1996), further allows the quantification of the density-independent variation in postsettlement survival. Through this, we (1) estimate the level of direct and delayed DDM in 11 areas (or fjords); (2) compare the importance of density-dependent processes vs. stochastic ones; and (3) quantify 


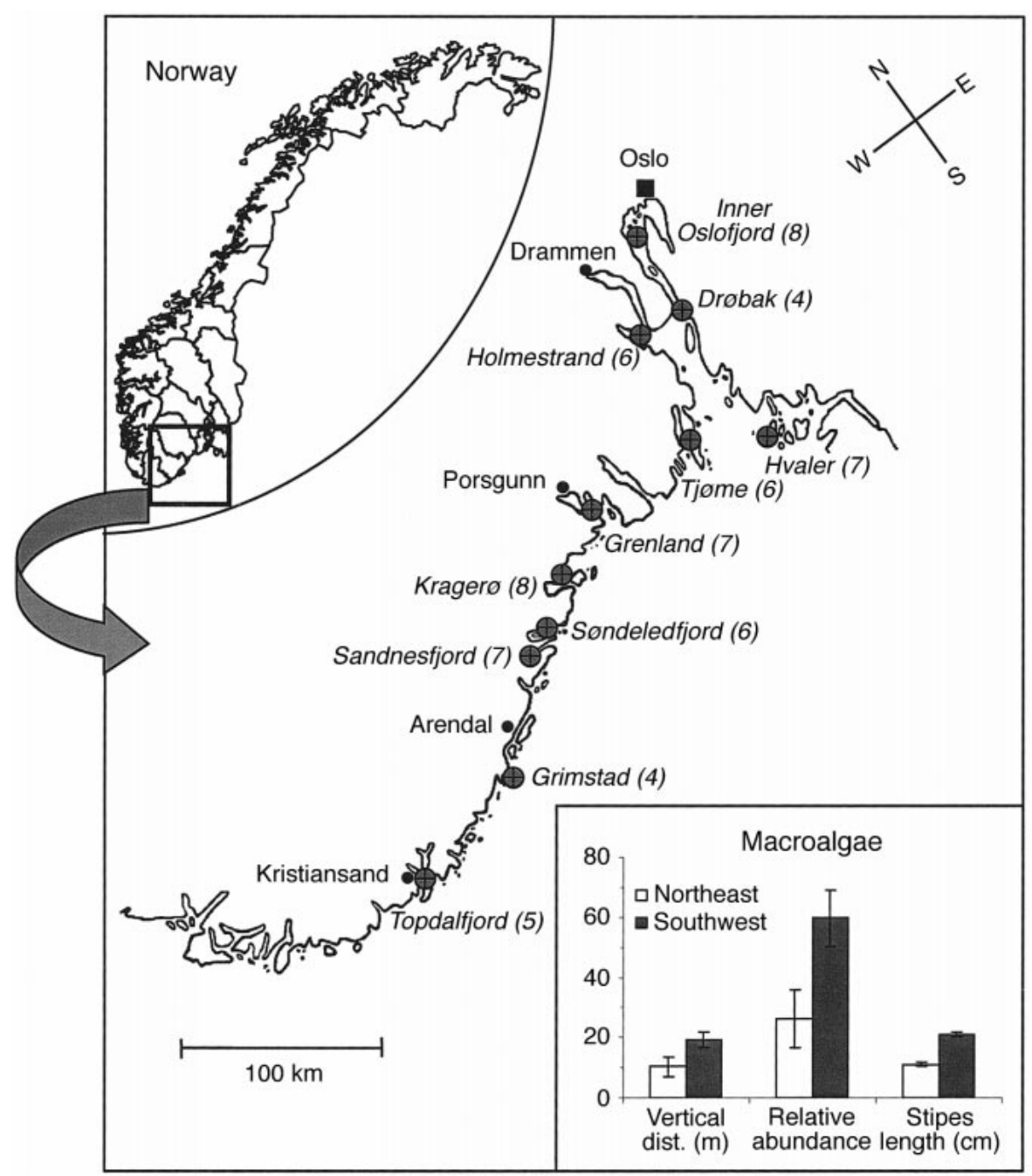

FIG. 1. The Norwegian Skagerrak coast within Norway together with a detailed map showing the locations of the 11 studied areas or fjords. The number of stations for each area or fjord is given in parentheses (68 stations in all). Sampling occurred once a year in September or October and started in 1919 or 1920 for the five southwestern areas (Topdalsfjord, Grimstad, Sandnesfjord, Søndeledfjord, and Kragerø), in 1936 for the five northeastern areas (Tjøme, Holmestrand, Oslofjord, Drøbak, and Hvaler), and in 1953 for Grenland. The lower right insert represents the vertical distribution, the relative abundance, and the stipes length of the macroalgae in the southwest and northeast of the Norwegian Skagerrak coast.

the degree of regulation in the Norwegian Skagerrak cod due to density-dependent interactions throughout the life cycle. The strength of DDM is also compared among fjords. Biogeographic differences are discussed in light of food limitation and habitat differences.

\section{Material And Methods}

\section{Cod populations along the Norwegian Skagerrak coast}

Spawning in cod populations along the Norwegian Skagerrak coast (Fig. 1) occurs in early March. Fish larvae stay in the water column; there they feed and metamorphose into juveniles around May to June. When they are 3-5 cm long (around July or August), they settle on the bottom. These young juveniles (i.e., the 0-group) and the older juveniles (i.e., the 1-group: $1.5 \mathrm{yr}$ old) are generally found in shallow waters and closer to the shore than the older individuals (Dahl 1906). Both juvenile groups have similar habitat preferences (Fromentin et al. 2000); whereas, the adults (>2 yr old) are found in deeper water (Gjøsæter et al. 1996, Dalley and Anderson 1997).

Juvenile habitat is mainly comprised of seagrass bed and kelp, and 0- and 1-groups generally feed on the associated fauna (Johannessen and Sollie 1994, Fjosne and Gjøsæter 1996). Abundance, diversity, and vertical distribution of macroalgae are lower in the northeastern than in the southwestern part of the study area (Fig. 1; data from Pedersen et al. 1994, Langfelt 1995, Moy et al. 1997). The relative abundance, the vertical distri- 
bution, and the stipes length of Laminaria hyperborea (the dominant algae species) are, furthermore, two times higher in the southwestern than in the northeastern part of the Norwegian Skagerrak coast (Pedersen et al. 1994).

Maturation occurs around two to three years of age (Gjøsæter et al. 1996, Stenseth et al. 1999). Tagging experiments indicated that the Norwegian Skagerrak cod populations are relatively isolated, with limited migration (individuals appear fjord specific) and limited interchange among individuals of other nearby areas, e.g., the open sea population from the Skagerrak (Danielssen 1969, Julliard et al. 2001).

\section{Sampling and data}

The time series on cod arise from the Flødevigen survey, within which the fish community has been sampled at more than 250 fixed stations along the Norwegian Skagerrak coast since 1919. Since its beginning, the sampling was run by only two scientists and according to the same protocol, so that the sampling is very consistent. Samples were taken with beach seines every September or October (Dannevig 1954, Johannessen and Sollie 1994). The seine was $40 \mathrm{~m}$ long and $3.7 \mathrm{~m}$ deep with a stretched mesh size of $1.5 \mathrm{~cm}$. In each end of the seines, there were two 20-m-long ropes (in a few stations where special circumstances made it necessary, slightly shorter or longer ropes were used since 1919, maximum range $10-30 \mathrm{~m})$. The area covered by one haul is up to $700 \mathrm{~m}^{2}\left(\sim 1000 \mathrm{~m}^{2}\right.$ with the $30-\mathrm{m}$ ropes). No compensation was made for difference in area covered, but the geometrical shape of the haul appears to be equally important. The maximum depth sampled varied among sites, but ranged from three to $15 \mathrm{~m}$.

For the present study, we focused on 68 stations providing long time series of 0-group and 1-group cod with very few missing values $(<5 \%)$. All the stations are grouped into 11 different fjords or areas (the distance between the most distant stations is $\sim 370 \mathrm{~km}$; Fig. 1). Topdalsfjord, Sandnesfjord, Søndeledfjord, and Grenland are fjords that are $\sim 20 \mathrm{~km}$ long; the latter being affected by heavy local industry. Grimstad and Krager $\varnothing$ are coastal areas that are protected from direct influence of the open sea by numerous islands. Both Tjøme and Hvaler are directly open to the Skagerrak (Hvaler being the most exposed). Holmestrand and Drøbak are at the entrance of the Oslofjord, which is largely open to the Skagerrak. The Inner Oslofjord is an enclosed area, separated from the open sea by a very shallow threshold. This area has been strongly affected by human activities since the beginning of the $20^{\text {th }}$ century.

These 11 areas were selected because they contain a sufficient number of stations to obtain reliable quantification of the observation errors (see Materials and methods: Quantifying observation errors). Each area includes from four to eight stations (Fig. 1). Time series extend from 1919 or 1920 to 1996 for the five southwestern areas (Topdalsfjord, Grimstad, Sandnesfjord, Søndeledfjord, and Kragerø), from 1936 to 1996 for the five northeastern areas, (Tjøme, Holmestrand, Oslofjord, Drøbak, and Hvaler), and from 1953 to 1996 for Grenland. As the sampling occurred once a year and was interrupted only during the Second World War, time series include 72 or 73 values for the five southwestern areas, 56 for the five northeastern ones, and 44 for Grenland.

\section{Modeling direct density-dependent mortality}

Let $N_{0, t}$ and $N_{1, t}$ denote the number of fish in the 0group and the 1-group cod during the year $t$. Let $\varepsilon_{t}$ denote the random component of the density-independent mortality. If we now consider that direct densitydependent mortality (direct DDM) may arise from competition or cannibalism within the 0-group, a general model for the survival of the 0 -group to the 1 -group may be written as

$$
N_{1, t}=N_{0, t-1} \exp \left[f\left(N_{0, t-1}, \varepsilon_{t}\right)\right]
$$

where $f\left(N_{0, t-1}, \varepsilon_{t}\right)$ is a strictly negative function, so that $\exp \left[f\left(N_{0, t-1}, \varepsilon_{t}\right)\right]$ represents the proportion of the 0 group that survives in the following year. A Gompertz model was used because Bjørnstad et al. (1999a) showed that the survival of the Norwegian Skagerrak cod is approximately log-linearly related to the abundance (and not as often assumed linearly related to the abundance, see also Myers and Cadigan 1993a), so that

$$
N_{1, t}=N_{0, t-1} \exp \left[-m+\alpha \log _{e}\left(N_{0, t-1}+\varepsilon_{t}\right)\right]
$$

where $m$ is the average density-independent mortality (constant and positive), and $\alpha$ is a negative constant indicating the strength of the direct DDM ( $\alpha=0$ implying no direct DDM). The last term, $\varepsilon_{t}$, is a random variable (with zero mean) that represents stochastic year-to-year variation in mortality.

Let $X_{t}=\log _{e}\left(N_{0, t}\right)$ and $Y_{t}=\log _{e}\left(N_{1, t}\right)$. Then, taking the natural logarithms on both sides of Eq. 2 and collecting terms we get the following equation:

$$
Y_{t}=-m+(1+\alpha) X_{t-1}+\varepsilon_{t} .
$$

We assume that the survey data of the 0-group, $x_{t}$, and the 1-group, $y_{t}$, are measured with errors, which are proportional to the true abundance (which is equivalent to assuming that the log-transformed survey data are measured with additive errors). We define $\delta_{t, x}$ and $\delta_{t, y}$ as the observation errors of the log-transformed data of the 0-group and the 1-group, respectively. We assume the catchability to be independent of abundance (see Discussion: Density-dependent mortality), and let $c_{x}$ and $c_{y}$ represent the respective log catchability. We may then write the measurement process for the data on the 0- and 1-group abundance as follows:

$$
x_{t}=X_{t}+\mathrm{c}_{x}+\delta_{t, x} \quad y_{t}=Y_{t}+\mathrm{c}_{y}+\delta_{t, y} .
$$

Technically speaking, we assume the measurement 
process to follow the "Berkson model" after log transformation (Carroll et al. 1995). To estimate the biological parameters of Eq. 3 from the census counts, as governed by Eq. 4, we make the following set of assumptions. (1) The log-transformed standardized data of the true abundance of the 0-group in a given year is drawn from a time-invariant normal distribution with mean $\mu$ and constant variance $\phi$. That is, $X_{t} \sim \mathcal{N}(\mu$, $\phi)$. Note that the $X_{t}$ may be correlated without affecting the estimations. In a strict sense, we assume that the $X_{t}$ are multivariate normal with expectation $\mu$ and a covariance matrix that has the same variance for all observations (but possibly with off-diagonal elements to capture the correlation structure). (2) The year-toyear density-independent variability (stochastic), $\varepsilon_{t}$, is normally distributed and independent of year with zero mean and constant variance: $\varepsilon_{t} \sim \mathcal{N}(0, \psi)$. (3) The observation errors, $\delta_{t, x}$, and $\delta_{t, y}$, are unbiased, independent, and normally distributed on the log scale (Myers and Cadigan 1993a). The error variances are denoted by $\theta_{x}$ and $\theta_{y}$, so that: $\delta_{t, x} \sim \mathcal{N}\left(0, \theta_{x}\right)$ and $\delta_{t, y} \sim \mathcal{N}(0$, $\left.\theta_{y}\right)$.

We estimate $\theta_{x}$ and $\theta_{y}$ separately using the repeated sampling within each area (see Materials and methods: Quantifying observation errors). The catchability constants, $c_{x}$ and $c_{y}$, and the average density-independent mortality rate, $m$, cannot be estimated from the data. Therefore, we estimate the biological parameters in Eq. 3 from the centered time series. We estimate the unknown parameters using the variance-component model proposed by Myers and Cadigan $(1993 a, b)$, which fits a theoretical variance-covariance matrix to that observed between the time series of the log-transformed 0 -group in year $t-1$ and the 1 -group in year $t$. The theoretical variance-covariance matrix, $\mathbf{\Sigma}$, between the log-transformed 0 -group in year $t-1$ and 1 -group in year $t$ resulting from Eqs. 3 and 4 is

$$
\begin{aligned}
\boldsymbol{\Sigma} & =\left[\begin{array}{cc}
\operatorname{Var}\left(x_{t-1}\right) & \operatorname{Cov}\left(x_{t-1}, y_{t}\right) \\
\operatorname{Var}\left(y_{t}\right)
\end{array}\right] \\
& =\left[\begin{array}{cc}
\phi+\theta_{x} & (1+\alpha) \phi \\
& (1+\alpha)^{2} \phi+\psi+\theta_{y}
\end{array}\right] .
\end{aligned}
$$

The unknown parameters $\alpha, \phi$, and $\psi$ are estimated using maximum likelihood (Bollen 1989). This estimation was carried out using PROC CALIS in SAS Version 6.12 (SAS 1996).

\section{Modeling delayed density-dependent mortality}

Density-dependent mortality in juveniles may also result from competitive and/or cannibalistic interactions among individuals of the 0 - and the 1-group in a given year. Because these interactions can be seen as interactions between the 0-group in year $t$ and the 0group in year $t-1$, these are often referred to as delayed density-dependent mortality (delayed DDM). Adding this additional source of mortality to Eq. 2, we obtain the following:

$$
\begin{aligned}
N_{1, t}=N_{0, t-1} \exp [ & -m+\alpha \log _{e}\left(N_{0, t-1}\right) \\
+ & \left.\beta \log _{e}\left(N_{0, t-2}\right)+\varepsilon_{t}\right]
\end{aligned}
$$

where $\beta$ is a negative constant representing the strength of the delayed DDM; $\beta=0$ indicates no delayed DDM.

One difficulty when estimating delayed DDM is related to the presence of trends in the data (Myers and Cadigan 1993a, Williams and Liebhold 1995). Longterm fluctuations lead to positive autocorrelation at lag1 and might, therefore, blur the presence of significant delayed DDM, which would result in a negative autocorrelation at lag-1. When trends are conspicuous, estimates of $\beta$ will be biased and may appear positive. We circumvent this problem by also considering shorter periods, which were selected (1) to reduce as much as possible the confounding influence of the long-term fluctuations; (2) to make series with relatively similar time periods for the different areas; and (3) to obtain nonsignificant correlation in the residuals. We have chosen to work on shorter periods rather than detrending the series, because detrending affects the autocovariance in the data and can lead to biases in the DDM parameters. A second difficulty relates to our assumption of independent observation errors. This assumption can be violated because we now consider two estimates of abundance during each year $\left(X_{t-1}\right.$ and $\left.Y_{t-1}\right)$. If some latent factors (e.g., environmental ones) affect both groups, then the counts of $X_{t-1}$, and $Y_{t-1}$ may be correlated. Such effects are well known in surveys of cod (Myers and Cadigan 1995). Therefore, we allow for a covariance, $\rho$, among the observation errors within each year; that is, $\rho=\operatorname{Cov}\left(\delta_{t, x}, \delta_{t, y}\right)$.

Previous assumptions still apply, but instead of estimating a $2 \times 2$ variance-covariance matrix we now estimate a $4 \times 4$ covariance matrix among the following set of log abundances $\left(X_{t-1}, X_{t-2}, Y_{t}, Y_{t-1}\right)$ :

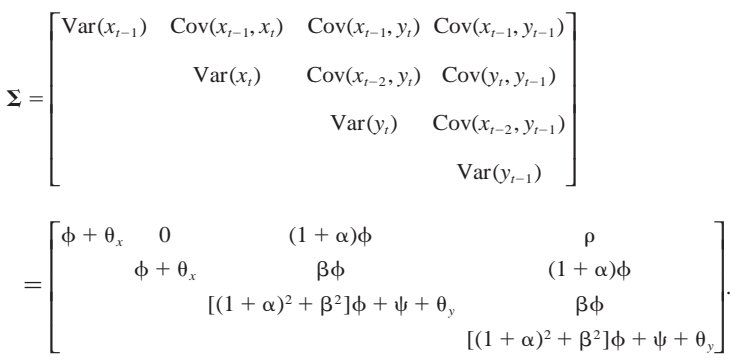

The unknown parameters, $\alpha, \phi, \psi, \beta$, and $\rho$, are estimated from the observed variance-covariance matrix using maximum likelihood. Thus, the above formulation can be considered as an extension of the key factor analysis, since the model further corrects for observation errors.

\section{Quantifying observation errors}

The presence of observation errors can blur the estimates of direct $(\alpha)$ and delayed ( $\beta$ ) DDM, density- 


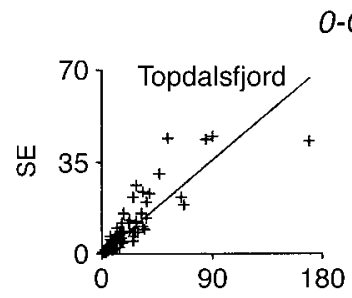

\section{0-Group}
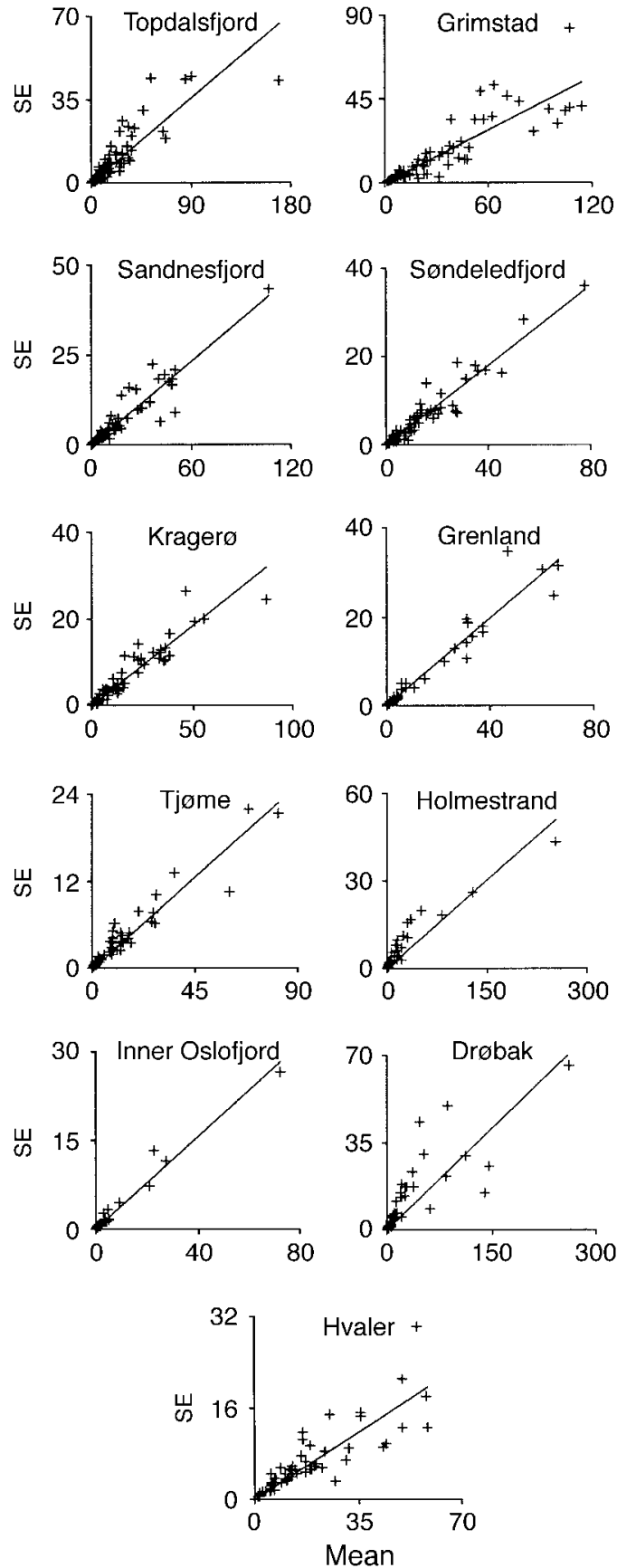

1-Group
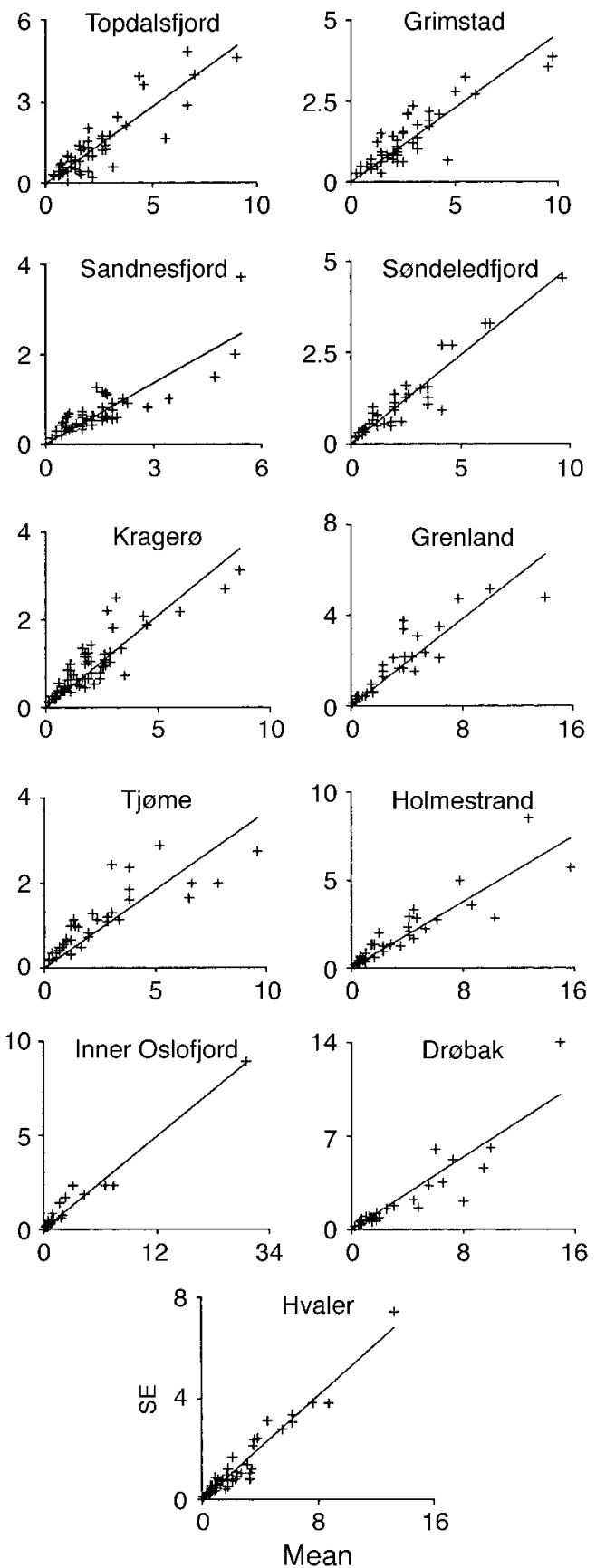

FIG. 2. Relationships between the mean and the standard error (SE) in the 11 areas for the 0-group cod (left side) and the 1-group (right side). The series were calculated using the raw data from all the stations of a given area (each area including four to eight stations). Straight lines correspond to the linear regression, forced through the origin, between the standard error and the mean.

independent variability in survival $(\psi)$, and variability in the 0-group $(\phi)$. To correct for this bias, our modeling approach integrated these observation errors into the structure of the model (Eq. 4). We quantified observation error variance by using the repeated sampling within each area. Since each area included four to eight stations, we computed the mean abundance and its standard error across all the stations for each year (means and standard errors were calculated on raw data excluding the years with missing values). We then in- 
TABLE 1. Estimates (with $1 \mathrm{SE}$ in parentheses) of direct DDM $(\alpha)$, corrected variability in the 0-group $(\phi)$, and stochastic variability in survival from the 0-group to the 1-group $(\psi)$, for each area or fjord, using the simple model (Eq. 2).

\begin{tabular}{lcccccc}
\hline \hline \multicolumn{1}{c}{ Fjord } & $\theta_{x}$ & $\theta_{y}$ & $\alpha$ & $\phi$ & $\psi$ & Period \\
\hline Topdalsfjord & 0.34 & 0.44 & $-0.30(0.14)$ & $0.99(0.22)$ & $0.39(0.17)$ & complete \\
Grimstad & 0.38 & 0.38 & $-0.07(0.13)$ & $1.04(0.24)$ & $0.24(0.16)$ & complete \\
Sandnesfjord & 0.33 & 0.37 & $-0.43(0.11)$ & $1.29(0.27)$ & $0.35(0.14)$ & complete \\
Søndeledfjord & 0.37 & 0.39 & $-0.28(0.12)$ & $1.35(0.29)$ & $0.40(0.16)$ & complete \\
Kragerø & 0.37 & 0.35 & $-0.27(0.13)$ & $0.93(0.21)$ & $0.31(0.14)$ & complete \\
Grenland & 0.41 & 0.39 & $-0.50(0.12)$ & $2.75(0.70)$ & $0.98(0.32)$ & complete \\
Tjøme & 0.25 & 0.32 & $-0.25(0.10)$ & $1.82(0.42)$ & $0.42(0.17)$ & complete \\
Holmestrand & 0.18 & 0.39 & $-0.33(0.10)$ & $2.00(0.42)$ & $0.46(0.19)$ & complete \\
Oslofjord & 0.33 & 0.34 & $-0.36(0.12)$ & $2.25(0.61)$ & $0.50(0.23)$ & complete \\
Drøbak & 0.24 & 0.51 & $-0.27(0.10)$ & $2.15(0.46)$ & $0.27(0.17)$ & complete \\
Hvaler & 0.29 & 0.41 & $0.19(0.19)$ & $0.69(0.18)$ & $0.07(0.17)$ & complete \\
\hline
\end{tabular}

Note: The variances in the observation errors for the 0 -group $\left(\theta_{x}\right)$ and the 1-group $\left(\theta_{y}\right)$ were directly estimated from the relationship between the mean and the SE (Fig. 2).

TABLE 2. Same as Table 1, but assuming a 50\% higher variance of the observation errors of the 0-group.

\begin{tabular}{|c|c|c|c|c|c|c|}
\hline Fjord & $\theta_{x}$ & $\theta_{y}$ & $\alpha$ & $\phi$ & $\psi$ & Period \\
\hline Topdalsfjord & 0.51 & 0.44 & $-0.16(0.18)$ & $0.82(0.22)$ & $0.39(0.17)$ & complete \\
\hline Grimstad & 0.57 & 0.38 & $0.10(0.19)$ & $0.87(0.27)$ & $0.06(0.19)$ & complete \\
\hline Sandnesfjord & 0.49 & 0.37 & $-0.30(0.13)$ & $1.13(0.27)$ & $0.29(0.15)$ & complete \\
\hline Søndeledfjord & 0.55 & 0.39 & $-0.17(0.14)$ & $1.17(0.29)$ & $0.39(0.18)$ & complete \\
\hline Krager $\varnothing$ & 0.55 & 0.35 & $-0.02(0.21)$ & $0.68(0.2)$ & $0.14(0.17)$ & complete \\
\hline Grenland & 0.61 & 0.39 & $-0.46(0.13)$ & $2.54(0.70)$ & $0.92(0.33)$ & complete \\
\hline Tjøme & 0.37 & 0.32 & $-0.20(0.11)$ & $1.70(0.40)$ & $0.42(0.17)$ & complete \\
\hline Holmestrand & 0.27 & 0.39 & $-0.30(0.10)$ & $1.91(0.42)$ & $0.45(0.19)$ & complete \\
\hline Oslofjord & 0.49 & 0.34 & $-0.31(0.13)$ & $2.09(0.61)$ & $0.43(0.23)$ & complete \\
\hline Drøbak & 0.36 & 0.51 & $-0.22(0.10)$ & $2.02(0.46)$ & $0.20(0.18)$ & complete \\
\hline Hvaler & 0.43 & 0.41 & $0.52(0.32)$ & $0.54(0.18)$ & $0.00(0.23)$ & complete \\
\hline
\end{tabular}

TABLE 3. Same as Table 1, but assuming a 50\% lower variance of the observation errors of the 0-group.

\begin{tabular}{|c|c|c|c|c|c|c|}
\hline Fjord & $\theta_{x}$ & $\theta_{y}$ & $\alpha$ & $\phi$ & $\psi$ & Period \\
\hline Topdalsfjord & 0.17 & 0.44 & $-0.40(0.11)$ & $1.16(0.22)$ & $0.46(0.16)$ & complete \\
\hline Grimstad & 0.19 & 0.38 & $-0.22(0.11)$ & $1.33(0.24)$ & $0.38(0.15)$ & complete \\
\hline Sandnesfjord & 0.17 & 0.37 & $-0.49(0.09)$ & $1.45(0.27)$ & $0.40(0.14)$ & complete \\
\hline Søndeledfjord & 0.19 & 0.39 & $-0.36(0.10)$ & $1.52(0.29)$ & $0.48(0.16)$ & complete \\
\hline Krager & 0.19 & 0.35 & $-0.36(0.11)$ & $1.05(0.21)$ & $0.37(0.14)$ & complete \\
\hline Grenland & 0.21 & 0.39 & $-0.53(0.11)$ & $2.94(0.70)$ & $1.02(0.32)$ & complete \\
\hline Tjøme & 0.13 & 0.32 & $-0.30(0.10)$ & $1.95(0.40)$ & $0.49(0.17)$ & complete \\
\hline Holmestrand & 0.14 & 0.39 & $-0.34(0.10)$ & $2.04(0.42)$ & $0.60(0.19)$ & complete \\
\hline Oslofjord & 0.17 & 0.34 & $-0.40(0.11)$ & $2.41(0.61)$ & $0.56(0.23)$ & complete \\
\hline Drøbak & 0.12 & 0.51 & $-0.31(0.10)$ & $2.27(0.46)$ & $0.33(0.17)$ & complete \\
\hline Hvaler & 0.15 & 0.41 & $-0.01(0.24)$ & $0.83(0.18)$ & $0.23(0.15)$ & complete \\
\hline
\end{tabular}

vestigated, in each area, the relationship between the mean and its standard error. The standard error was approximately proportional to the mean in all cases (Fig. 2), as assumed in the model. Thus, the observation errors can be approximated by a log normal process, so that errors in log abundance are approximately normal. The variances, $\theta_{x}$ and $\theta_{y}$, can then be estimated on the basis of the raw data by a linear regression, forced through the origin, between the standard deviations and the means (Johnson et al. 1994). We tested for robustness of the model estimations by considering $\theta_{x}$ estimates $\pm 50 \%$. The results (Tables 1,2 , and 3 ) indicate that the model tends to slightly underestimate $\alpha$, and to overestimate $\phi$ and $\psi$ when $\theta_{x}$ was $50 \%$ larger, and vice versa when $\theta_{x}$ was $50 \%$ lower. However, differences were small and in most of the cases nonsignificant, indicating a good robustness of the model to misspecification of the observation error variances.

\section{Dealing with zero catches and missing values}

Subsequent to the estimation of $\theta_{x}$ and $\theta_{y}$, we averaged abundance of the 0-group and of the 1-group over all stations within each area. When a missing value occurred for a given year in a given station, we imputed the value using the prediction from a contingency table (a generalized linear model, GLM, with a station and a year effect, a log link, and a Poisson error; see McCullagh and Nelder 1989). The Spearman rank cor- 


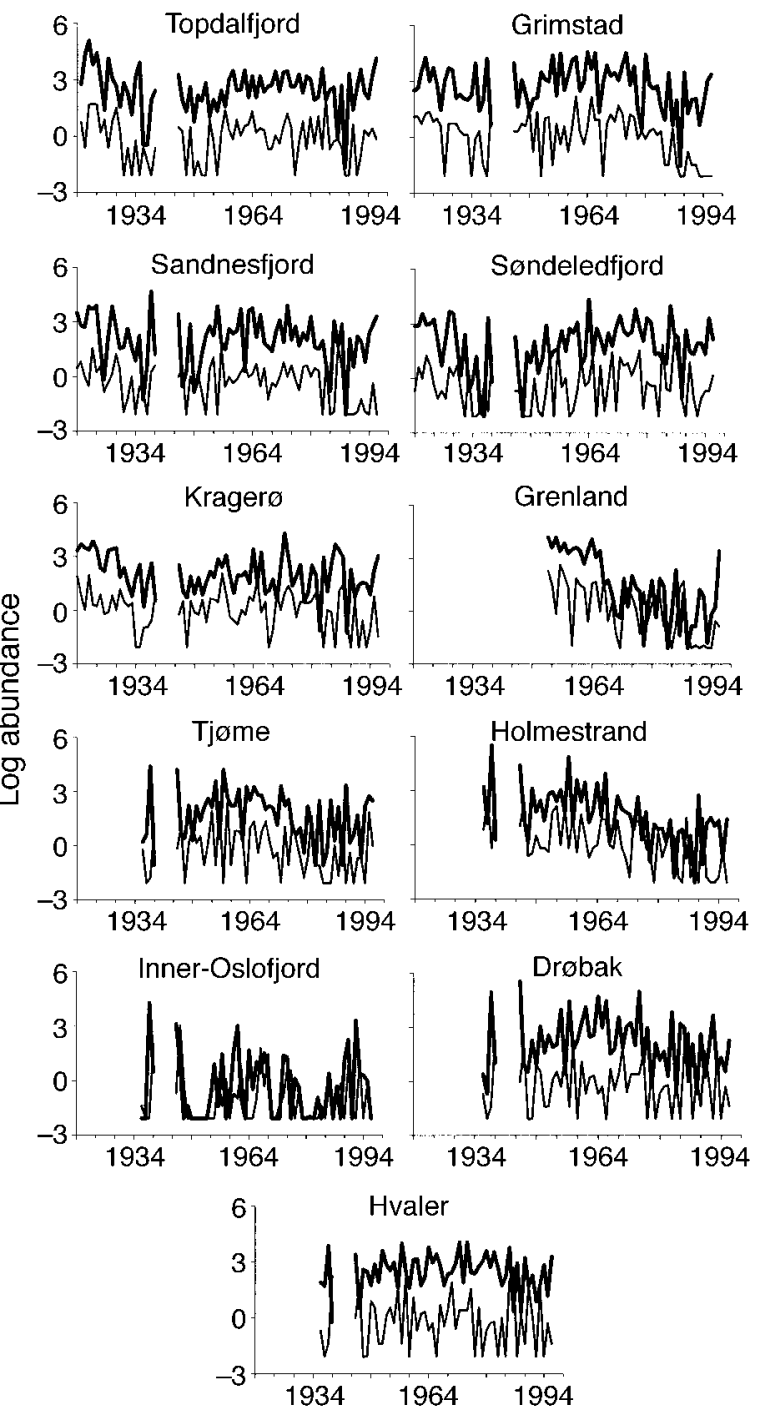

FIG. 3. Averaged time series of 0-group (bold line) and of 1-group (solid line) cod for 11 areas or fjords. Times series were obtained by averaging the abundance of the 0 -group and of the 1-group over all the stations of a given area, and taking the $\log$ of these averages (zero observations were set to $\left.\log _{e}(0.125)\right)$.

relations between predicted and observed were always $>0.99$. Further tests showed that predicted means were always very close to observed ones. Averaged series were then $\log$ transformed, and each average equal to zero was replaced by $\log _{e}(0.125)$. The value of 0.125 was chosen because it is the lowest mean in all the surveys. (To test for robustness, we also estimated the different parameters excluding the values with zero catches: the differences were very small and never significant). After averaging, we obtained 11 time series of the 0-group and the 1-group (Fig. 3). Note how the $\log _{\mathrm{e}} 0$-group at time $t$ and the $\log _{\mathrm{e}} 1$-group at time $t+1$ displayed clear relationships within all the fjords (Fig. 4).

\section{Checking for regulation and tests of robustness}

According to theory, regulation in juvenile cod populations occurs if direct and delayed density-dependent processes, as measured by $\alpha$ and $\beta$, reduce the variability generated by stochastic factors, as measured by $\psi$ and partly by $\phi$. Thus, we consider regulation as "relative stabilization" (see also Introduction). To test for regulation and to check subsequently for the validity of the model's estimates, we quantified the variability in the 0-group and 1-group cod by the coefficient of variation $(\mathrm{CV}$, the standard deviation scaled by the mean, e.g., Pimm 1991, Sokal and Rohlf 1995). The $\mathrm{CV}$ is an invariant (scale free) measure of variability, and is, therefore, well suited to compare relative variability among series (Hilborn and Mangel 1997). We computed the $\mathrm{CV}$ on the raw data of both groups in each area and used the ratio between the $\mathrm{CV}$ of the 1group and the 0-group as our index of regulation: a ratio $<1.0$ implies that some degree of regulation oc-

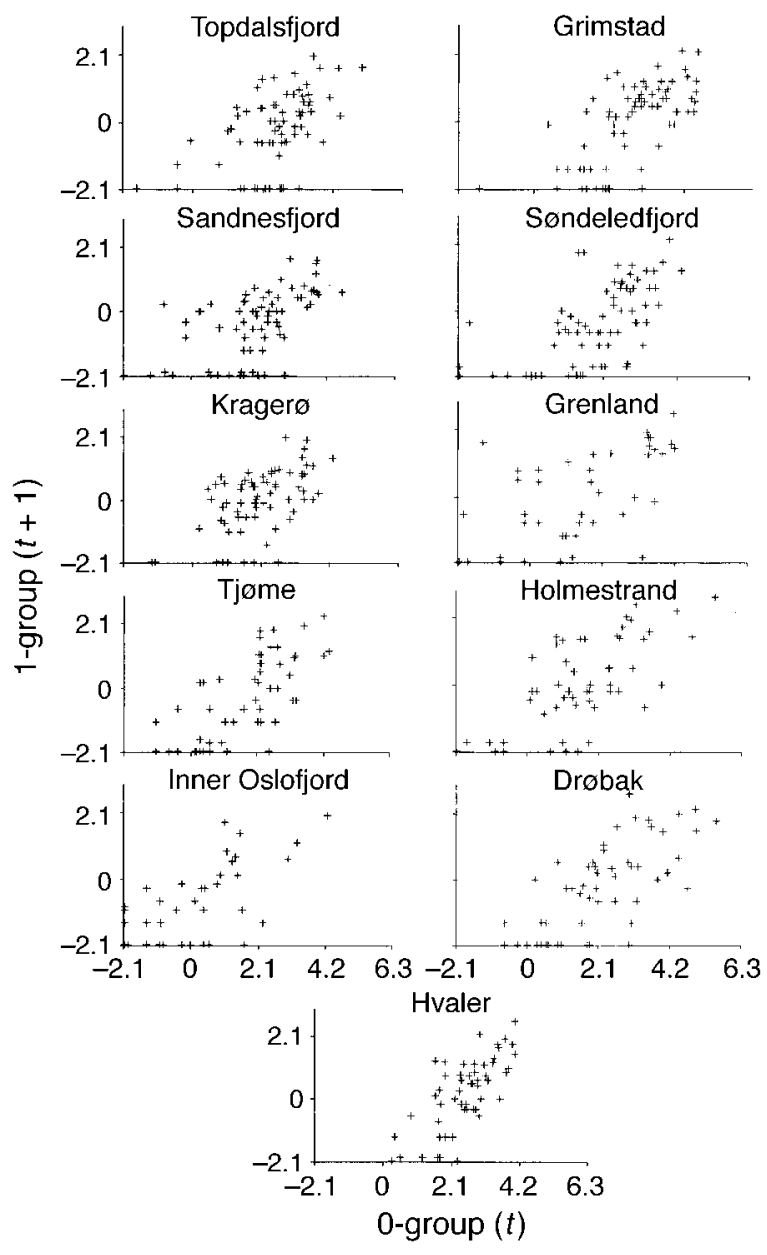

FIG. 4. Relationships between the $\log _{e} 0$-group at time $t$ ( $x$-axis) and the $\log _{e} 1$-group at time $t+1$ ( $y$-axis) for each area. 
TABLE 4. Estimates $( \pm 1$ SE) of direct DDM $(\alpha)$, delayed-DDM $(\beta)$, corrected variability in the 0-group $(\phi)$, stochastic variability in survival from the 0 -group to the 1-group $(\psi)$, and the covariance in the observation errors $(\rho)$ for each area, using the full model (Eq. 5).

\begin{tabular}{lcccrrrrc}
\hline \hline \multicolumn{1}{c}{ Fjord } & $\theta_{x}$ & $\theta_{y}$ & $\alpha$ & $\beta$ & $\phi$ & $\psi$ & \multicolumn{1}{c}{$\rho$} & Period \\
\hline Topdalsfjord & 0.34 & 0.44 & $-0.27(0.10)$ & $0.24(0.15)$ & $0.97(0.16)$ & $0.37(0.12)$ & $0.19(0.11)$ & complete \\
Grimstad & 0.38 & 0.38 & $-0.03(0.10)$ & $0.26(0.16)$ & $1.00(0.17)$ & $0.19(0.11)$ & $0.03(0.10)$ & complete \\
Sandnesfjord & 0.33 & 0.37 & $-0.47(0.07)$ & $0.19(0.21)$ & $1.41(0.21)$ & $0.32(0.10)$ & $0.19(0.11)$ & complete \\
Søndeledfjord & 0.37 & 0.39 & $-0.31(0.08)$ & $0.26(0.21)$ & $1.43(0.22)$ & $0.41(0.12)$ & $0.03(0.12)$ & complete \\
Kragerø & 0.37 & 0.35 & $-0.22(0.10)$ & $0.23(0.14)$ & $0.86(0.15)$ & $0.27(0.10)$ & $-0.03(0.10)$ & complete \\
Grenland & 0.41 & 0.39 & $-0.49(0.08)$ & $2.17(0.64)$ & $3.04(0.64)$ & $0.92(0.22)$ & $0.02(0.24)$ & complete \\
Tjøme & 0.25 & 0.32 & $-0.23(0.07)$ & $-0.35(0.28)$ & $1.79(0.28)$ & $0.39(0.12)$ & $0.19(0.12)$ & complete \\
Holmestrand & 0.18 & 0.39 & $-0.34(0.07)$ & $-0.03(0.30)$ & $2.15(0.30)$ & $0.53(0.14)$ & $-0.03(0.15)$ & complete \\
Oslofjord & 0.33 & 0.34 & $-0.35(0.07)$ & $0.16(0.52)$ & $2.8(0.53)$ & $0.36(0.14)$ & $0.11(0.18)$ & complete \\
Drøbak & 0.24 & 0.51 & $-0.26(0.06)$ & $-0.67(0.34)$ & $2.18(0.34)$ & $0.17(0.13)$ & $-0.17(0.14)$ & complete \\
Hvaler & 0.29 & 0.41 & $0.30(0.15)$ & $-0.21(0.11)$ & $0.63(0.13)$ & $0(0.12)$ & $0.08(0.08)$ & complete \\
\hline
\end{tabular}

Note: The variances in the observation errors for the 0 -group $\left(\theta_{x}\right)$ and the 1-group $\left(\theta_{y}\right)$ remain the same.

TABLE 5. Same as in Table 4 for shorter periods (indicated in the last column), which did not exhibit long-term fluctuations.

\begin{tabular}{lcccrrrrc}
\hline \hline \multicolumn{1}{c}{ Fjord } & $\theta_{x}$ & \multicolumn{1}{c}{$\theta_{y}$} & $\alpha$ & \multicolumn{1}{c}{$\beta$} & \multicolumn{1}{c}{$\phi$} & $\psi$ & $\rho$ & Period (years) $\dagger$ \\
\hline Topdalsfjord & 0.34 & 0.44 & $-0.33(0.12)$ & $0.04(0.15)$ & $0.84(0.15)$ & $0.38(0.13)$ & $0.09(0.12)$ & $25-39+50-96$ \\
Grimstad & 0.38 & 0.38 & $-0.10(0.14)$ & $-0.05(0.14)$ & $0.72(0.16)$ & $0.19(0.12)$ & $0.03(0.11)$ & $25-39+45-82$ \\
Sandnesfjord & 0.33 & 0.37 & $-0.48(0.09)$ & $0.08(0.20)$ & $1.19(0.20)$ & $0.35(0.11)$ & $0.11(0.13)$ & $25-39+45-82$ \\
& & & & & & & & $+89-96$ \\
Søndeledfjord & 0.37 & 0.39 & $0.11(0.19)$ & $-0.14(0.14)$ & $0.68(0.13)$ & $0.38(0.18)$ & $0.09(0.13)$ & $50-96$ \\
Kragerø & 0.37 & 0.35 & $-0.17(0.13)$ & $0.01(0.17)$ & $0.84(0.18)$ & $0.24(0.13)$ & $0.004(0.12)$ & $50-96$ \\
Grenland & 0.41 & 0.39 & $-0.62(0.20)$ & $0.09(0.34)$ & $1.36(0.35)$ & $1.13(0.31)$ & $0.13(0.31)$ & $67-96$ \\
Tjøme & 0.25 & 0.32 & $-0.13(0.11)$ & $-0.49(0.27)$ & $1.31(0.28)$ & $0.3(0.14)$ & $0.02(0.13)$ & $36-39+45-77$ \\
Holmestrand & 0.18 & 0.39 & $-0.50(0.10)$ & $-0.65(0.32)$ & $1.61(0.33)$ & $0.45(0.15)$ & $0.13(0.17)$ & $36-39+45-77$ \\
Oslofjord & 0.33 & 0.34 & $-0.41(0.09)$ & $-0.20(0.72)$ & $2.84(0.73)$ & $0.39(0.19)$ & $0.01(0.26)$ & $36-39+55-77$ \\
Drøbak & 0.24 & 0.51 & $-0.32(0.08)$ & $-0.75(0.42)$ & $2.09(0.42)$ & $0.25(0.15)$ & $-0.08(0.17)$ & $36-39+45-77$ \\
Hvaler & 0.29 & 0.41 & $0.30(0.15)$ & $-0.21(0.11)$ & $0.63(0.13)$ & $0.00(0.12)$ & $0.08(0.08)$ & complete \\
\hline
\end{tabular}

$\dagger$ Periods are reported in terms of the last two digits of years (e.g., “25-39” indicates 1925-1939).

curred. Using the CV allows us to make few assumptions and to work directly on raw data.

\section{RESULTS}

\section{Direct density dependence}

We first estimated direct DDM $(\alpha)$ within the 0-group cod without considering delayed DDM (Eq. 2). Most of the areas displayed significant $\alpha$ within a range of $0.25-0.50$ (Table 1). These values lead to moderate to strong direct DDM; $\alpha$ values of 0.50 or 0.25 imply that a 100 -fold increase in the 0 -group cod only results in a 10-fold or a 32 -fold increase in the 1-group, respectively. Two areas, Grimstad and Hvaler, exhibited nonsignificant $\alpha$. Thus, the strength of direct DDM appears specific to each fjord or population.

The ratio of the coefficient of variation of the 1-group and the 0-group is shown in Fig. 3. Except for Søndeledfjord (see Results: Delayed density dependence), the fjords displaying significant $\alpha$ had a CVratio $<1.0$, as predicted in the case of density-dependent regulation; whereas, the two areas displaying nonsignificant direct DDM (Grimstad and Hvaler) had a CV-ratio $>1.0$.

\section{Delayed density dependence}

Relaxing the assumption that only direct DDM occurs, we estimated both direct $(\alpha)$ and delayed DDM ( $\beta$ ) (Eq. 6). Estimates of $\alpha$ did not vary significantly between the two models (Tables 1 and 4). Estimates of $\beta$ were significantly positive for four of the five southwestern areas and for Grenland; whereas, estimates of $\beta$ were significantly negative for three of the five northeastern areas (Table 4). Significantly positive estimates of $\beta$ are likely to result from the presence of trends (see Materials and methods: Modeling delayed densitydependent mortality). The highly positive value for Grenland probably reflected the dramatic drop in abundance in the late 1960s; Fig. 3). Therefore, we estimated direct $(\alpha)$ and delayed DDM $(\beta)$ on shorter series.

On these series, the covariances among observation errors, $\rho$, were no longer significant for any area; i.e., the assumption of independence among observation errors was now respected (Table 5). Estimates of $\beta$ in the five southwestern areas and Grenland were no longer significantly positive, indicating that the effects of the trends were removed (Table 5). The $\beta$ 's in these six 


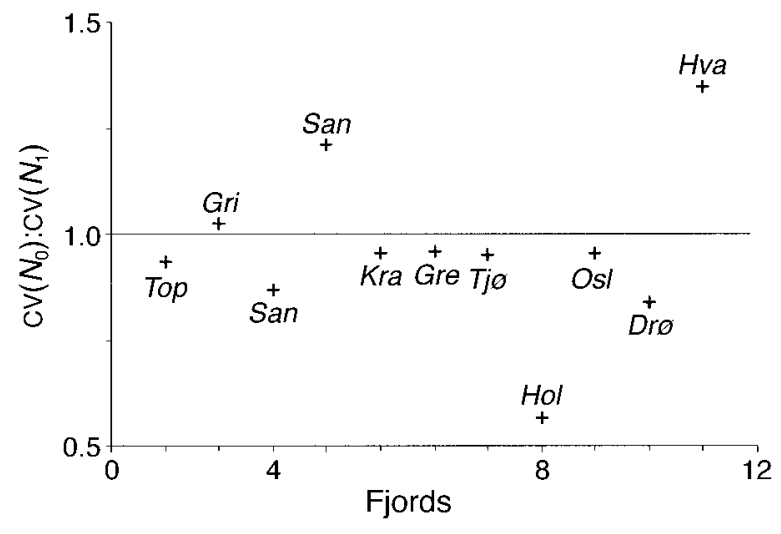

FIG. 5. Values of the ratios of the coefficients of variation of the 1-group, $\operatorname{CV}\left(N_{1}\right)$, to those of the 0-group, $\operatorname{CV}\left(N_{0}\right)$, for the 11 areas (identified by their first three letters). This ratio indicates whether the relative variability in the 1 -group is lower than $($ ratio $<1.0)$ or greater than $($ ratio $>1.0)$ the variability in the 0 -group.

areas were not significantly different from zero; i.e., there was no evidence suggesting delayed DDM. In contrast, $\beta$ s were significantly negative in four of the five northeastern areas (although nonsignificant, $\beta$ was also negative for Oslofjord). The estimates suggest that delayed DDM was especially strong in Tjøme, Holmestrand, and Drøbak.

Direct DDM estimates did not differ significantly when the model was run on shorter time series, except for Søndeledfjord. In this area, the estimate of $\alpha$ in the 1919-1939 period is equal to 0.5; whereas, it is zero in the 1945-1996 period. In contrast to all the other areas, this fjord displayed strong temporal heterogeneity, and the value of $\sim 0.30$ estimated for the 1919 1996 period appears to represent a temporal average. This temporal heterogeneity may reflect the transition in average abundance seen in the series (Fig. 3), and may further explain why the ratio $\mathrm{CV}\left(N_{1}\right): \mathrm{CV}\left(N_{0}\right)$ calculated across the 1919-1996 period was $>1.0$ (Fig. $5)$.

\section{Variability in the O-group}

The variability in the 0 -group $\operatorname{cod}(\phi)$ is estimated for the different areas by taking sampling errors into account (Tables 1-5). This corrected variability, $\phi$, reflects, among other things, stochastic variability in recruitment and/or in adult stock and fecundity. The level of $\phi$ differed among areas and appeared two times higher in the northeastern areas and Grenland than in the southwestern ones. The five southwestern areas displayed values $\sim 1.0$ (being $\sim 50 \%$ of the mean of these time series); whereas, Grenland and the northeastern areas (except Hvaler) exhibited higher variability in the 0 -group, with values $\geq 2.0$ (more than $100 \%$ of the mean of these time series).

\section{Stochastic variability in postsettlement survival}

The stochastic variability in survival of the 1-group from the 0-group $(\psi)$ was lower than the estimated variability in the 0 -group (Table 1 ). For most of the areas, $\psi$ was between 0.2 and 0.5 . In the five northeastern areas, $\psi$ represented $\sim 10-23 \%$ of the variability in the 0-group $(\phi)$, but $\psi$ reached $30-40 \%$ in three of the five southwestern areas (Topdalsfjord, Søndeledfjord, and Kragerø) as well as in Grenland. These results showed that the stochastic variability in postsettlement survival was substantial in the southwestern areas, even after accounting for direct and delayed DDM.

\section{DISCUSSION}

\section{Density-dependent mortality (DDM)}

This study confirms the presence of density-dependent mortality within the juveniles of the Norwegian Skagerrak cod populations (Fromentin et al. 1997, Bjørnstad et al. 1999a, Stenseth et al. 1999). It also provides additional evidence of the importance of DDM processes in temperate demersal fish populations (Myers and Cadigan 1993a). Disregarding spatial heterogeneity (see Discussion: Local differences), the range of the values of direct DDM imply that a 100fold increase in the 0-group cod would only result in a 10-30-fold increase in the 1-group. In addition, most of the northeastern areas displayed significant delayed DDM. Some of these estimates are $\geq 0.5$; that is large if we assume that the average density-independent mortality for fish older than $1 \mathrm{yr}$ is $\sim 0.4$ in these populations (an estimation based on capture-recapture modeling; Julliard et al. 2001).

DDM estimates ( $\alpha$ and $\beta$ ) might be underestimated because of the three months of delay between the date of the sampling (September or October) and the settlement of the young-of-the-year (May-July). The census survey of Tupper and Boutilier (1995a) on the Atlantic cod indicated that the postsettlement loss for the two months following the settlement ranged from $50 \%$ to near $100 \%$, and Levin (1994) found a loss of $~ 99 \%$ on temperate reef fish. During this period, cannibalism and competition occur (Tupper and Boutilier 1995 $a, b$, Borg et al. 1997). Therefore, DDM within the 0-group is likely to be important. Bromley et al. (1997) have further shown that pelagic 0-groups of whiting, cod, and haddock species were able to eat large prey items, so that larger individuals could eat slower growing ones from the same year class. Both cannibalism and interspecific predation were thus substantial for the pelagic 0-group of several Gadoid species of the northern North Sea. This may lead to an additional source of DDM mortality within the 0-group, that we are not able to detect.

The detection of DDM might result from emigration of the 0-group in neighborhood areas and/or in deeper waters during big year-class events. However, emigra- 
tion is unlikely to solely explain direct and delayed DDM, because Danielssen (1969) and Danielssen and Gjøsæter (1994) showed that these populations did not migrate much and appeared fjord specific. This conclusion was confirmed by Julliard et al. (2001) on the basis of a mark-recapture analysis. Another potential problem could result from density-dependent catchability, because of the aggregated distribution of juvenile stages, for instance. In that case, one assumption of our model would be violated, so that the detection of DDM processes could partially reflect changes in catchability. Such an hypothesis remains unlikely because (1) Bjørnstad et al. (1999a), using a model free approach at a regional scale, also demonstrated significant DDM in the Norwegian Skagerrak cod populations; and (2) the ratios of $\operatorname{CV}\left(N_{1}\right): \operatorname{CV}\left(N_{0}\right)$, which were calculated independently from the model, were in agreement with our DDM estimates (see Discussion: Regional differences and habitats of juvenile cod). Therefore, we believe that the detection of DDM processes is mainly related to biotic interactions, such as competition and cannibalism.

\section{Variability in the 0-group and stochastic variability in survival}

The variability within the 0-group $(\phi)$ was high in most of the areas. This probably reflects high fluctuations in the abundance of egg and fish larvae due to changes in environmental conditions and food availability (e.g., Cury and Roy 1989, Ellersten et al. 1989, Skreslet 1989, Cushing 1990, Dickson and Brander 1993, Ottersen and Sundby 1995, Sundby 1995). Note, however, that variability in the 0 -group could also reflect fluctuations in spawning stock biomass, in fecundity, density dependence in reproduction (if it exists), as well as DDM in the 0-group during the three months following the settlement.

An interesting additional feature is the presence, in some areas, of substantial variability in density-independent mortality from the 0-group to the 1-group $(\psi)$. This source of variation is usually neglected in research studies on exploited populations, such as cod, probably because of insufficiently long time series on juvenile stages. It is, however, of interest from an ecological point of view, because it points out that stochastic factors are not only important for egg and larval stages, as stated by the match-mismatch hypothesis (Cushing 1990), but also for juvenile stages.

The detection of strong DDM processes $(\alpha$ and $\beta)$ and substantial stochastic postsettlement survival $(\psi)$ suggest that the dynamics of the Norwegian Skagerrak cod is substantially affected by processes acting during juvenile stages. Therefore, variations in these populations could not be solely predicted from environmental data and larval surveys, as it is done for some northern fish populations. These findings are in agreement with the theoretical works of Mertz and Myers (1995) and Myers (1998). It would be of interest to

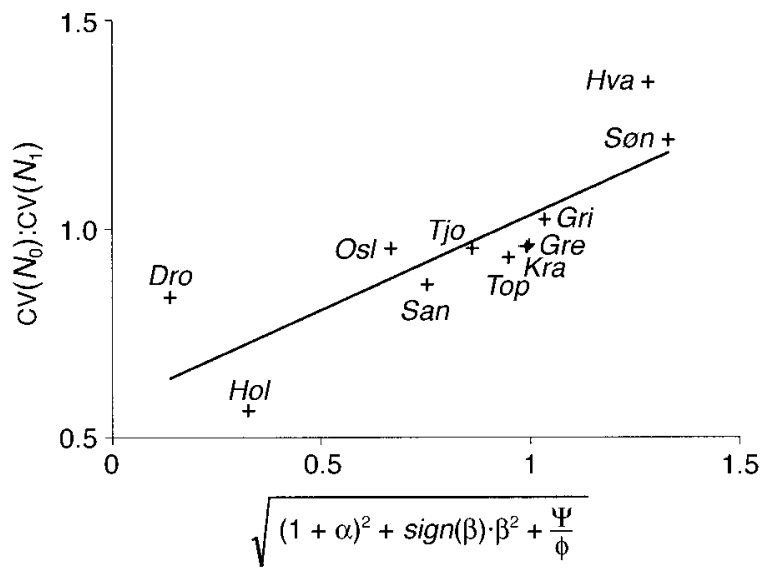

FIG. 6. Plot of the $\operatorname{CV}\left(N_{1}\right): \operatorname{CV}\left(N_{0}\right)$ ratio calculated on raw data plotted against the magnitude of DDM and stochastic parameters estimated in Table 5. $\beta$ is squared in the formula, so that the information related to the sign disappears. We need, however, to take the sign into account because only negative values of $\beta$ lead to regulation (positive $\beta$ 's on the contrary, increase the variability). Note that the expression $(1+\alpha)^{2}$ automatically takes the sign of $\alpha$ into account, so that we do not need further rectification. The abscissa is, therefore, given by $\sqrt{(1+\alpha)^{2}+\operatorname{sign}(\beta) \beta^{2}+\psi / \phi}$. The line of the linear regression is superimposed $\left(P=0.0016, r^{2}=\right.$ $0.68)$.

investigate whether these conclusions might be generalized to other commercial fish stocks.

\section{Regulation in cod populations}

We used our model estimates and the ratios of $\operatorname{CV}\left(N_{1}\right): \operatorname{CV}\left(N_{0}\right)$ to examine how much DDM processes have reduced the variability within the juvenile stages. The $\operatorname{CV}\left(N_{1}\right): \operatorname{CV}\left(N_{0}\right)$ against estimates of $\alpha$ indicate that direct DDM reduces the subsequent variability from the 0-group to the 1-group; that is, direct DDM appears to "regulate" the populations. We also detected significant delayed DDM, which may reinforce this regulation. Stochastic variability in survival, in contrast, should increase variation in the 1-group. According to Eqs. 6 and 7, the abundance of cod follows a conditional log normal process, for which $\mathrm{CV}\left(N_{1}\right) \approx \mathrm{SD}\left(\log _{\mathrm{e}}\left(N_{1}\right)\right)$, as long as the $\mathrm{CV}$ is small (Johnson et al. 1994) Thus, according to the model (see the $4 \times 4$ matrix), $\quad \operatorname{cv}\left(N_{0}\right) \approx \sqrt{\phi}$ and $\operatorname{cv}\left(N_{1}\right) \approx \sqrt{\left((1+\alpha)^{2}+\beta^{2}\right) \phi+\psi}$.

The theoretical ratio of $\operatorname{CV}\left(N_{1}\right): \operatorname{CV}\left(N_{0}\right)$ can be thus expressed as:

$$
\frac{C V\left(N_{1}\right)}{C V\left(N_{0}\right)} \approx \sqrt{(1+\alpha)^{2}+\beta^{2}+\frac{\psi}{\phi}} .
$$

The $\operatorname{CV}\left(N_{1}\right): \operatorname{CV}\left(N_{0}\right)$ should here decrease as a function of the magnitude of the DDM processes, as measured by $\alpha$ and $\beta$ (according to a quadratic function), and increase as a function of survival stochasticity $\psi$ (scaled by the initial variability, $\phi$ ). To understand the dynamical consequences of different degrees of DDM 
and stochastic processes, we investigated the function linking the degree of relative regulation, as measured on the raw data by $\operatorname{Cv}\left(N_{1}\right): \operatorname{CV}\left(N_{0}\right)$, and the magnitude of the estimates $\alpha, \beta, \phi$, and $\psi$. There is a fairly good linear relationship between the degree of regulation and the amplitude of the model estimates $\left(P=0.0016, r^{2}\right.$ $=0.68$; Fig. 6 ). The regulation of these coastal populations appears not only as a function of the strength of the direct and delayed DDM processes, but also as an interaction between DDM processes and stochastic factors. For instance, the Grenland area exhibited strong direct DDM $(\alpha)$, but a rather low degree of regulation because of a high stochastic variability in postsettlement survival $(\psi)$.

Using a combined modeling and estimation framework applied to long-term survey data on cod, we are thus able to quantify the relative importance of DDM and stochastic forces on the cod dynamics. The cod populations along the Norwegian Skagerrak coast constitute an interesting case study, because they span the range between areas where density dependence is strong enough to lead to regulation, and where stochastic processes are sufficiently strong to lead to increase in variability. The influence of stochastic variability is rarely considered explicitly in studies of density-dependent regulation, both in marine and terrestrial fields. We show, here, a case study where stochastic variations can, in some cases, neutralize the regulative effects of DDM.

\section{Local differences}

Most of the estimated parameters exhibited local differences. Hvaler and Grenland are the two locations that stand out the most. Hvaler is the most exposed area to the open sea and is also located at the mouth of the main river of the Norwegian Skagerrak coast, the Glomma. The water flow of the Glomma River more than doubles that of the second largest river along this coast, and it represents $60 \%$ and $70 \%$ of the total output of nitrogen and phosphorus from the Norwegian Skagerrak rivers. The Glomma River probably increases marine production locally, especially the planktonic food web. The very low level of DDM, the low variability in density-independent processes, and the high average abundance of the 0-group (the highest after Grimstad) and the 1-group (the highest) may indicate that food limitation is poorer in Hvaler.

The case of Grenland is different. Since 1950, this area has been subjected to heavy pollutant discharges coming directly from local industry. This pollution affected the entire local fish community and was probably the origin of the dramatic drop in the cod abundance during the late 1960s (Johannessen and Sollie 1994). The cod population in Grenland was characterized by strong direct DDM, no delayed DDM, very high variability in the 0-group, and the highest level of stochastic variability in survival. This population appears to be the most strongly influenced by stochastic pro- cesses. Pollution, thus, seems to disrupt the dynamics of the population.

\section{Regional differences and habitats of juvenile cod}

Besides local differences, there is evidence of regional differences. The southwestern and Grenland populations were mainly characterized by moderate to strong direct DDM, no delayed DDM, moderate variability in the 0-group (except for Grenland), and substantial stochastic variability in survival. Thus, we postulate that the year class strength results from stochastic planktonic survival of the fish eggs and larvae, and postsettlement competition among the young-of-theyear (the latter being possibly related to space and/or food limitation; see Caley et al. 1996, Hayes et al. 1996, and next paragraph). The northeastern populations (except Hvaler) exhibited moderate to strong direct DDM, strong delayed DDM, high variability in the 0-group, but low stochastic variability in survival. Hence, stochastic planktonic survival was probably more acute than for the southwestern areas. However, there was also a stronger impact of DDM processes on the dynamics of these populations, possibly because of (1) postsettlement competition within the 0-group, as for the southwestern areas; and (2) cannibalism from the 1-group on the 0-group (Bogstad et al. 1994), as indicated by the high delayed DDM.

Differences in the bottom flora may explain these regional differences between the northeast and the southwest of the Norwegian Skagerrak coast. Seagrass beds and kelp are known to offer shelter for juvenile cod (Keats et al. 1987, Noreide and Fosså 1992). Predation and cannibalism on the 0-group cod has been related to the quality and the quantity of shelters (Gjøsæter 1988, Tupper and Boutilier 1995a, b, Borg et al. 1997). As abundance, diversity, and vertical distribution of macroalgae are lower in the northeastern areas than in the southwestern ones (Fig. 1), shelter for the 0 -group may be better in the southwest. This may explain why the juvenile cod populations in the northeastern areas (except Hvaler) display stronger DDM.

The abundance of kelp and other algae may also influence food availability for the 0 - and 1-group cod. Abundance and species richness of mobile invertebrates, which were found in abundance in the stomachs of the 0-group cod (Fjøsne and Gjøsæter 1996), were related to the volume and the nature of the macroalgae (Christie 1995, 1997). The southwestern areas display a higher number of species of both faunal and floral epiphytes on kelp (Moy et al. 1997). Thus, more prey and a higher complexity of feeding grounds are likely to be found in these areas. This may also explain some of the regional differences in DDM strength.

Without in situ observations and experiments, we must remain cautious with conclusions about the origins of the regional differences in the components of the dynamics of the Norwegian Skagerrak cod populations. It is, however, of interest to note that the re- 
gional patterns in habitat of juvenile cod correlate with the regional differences in the DDM and stochastic parameters.

Thus, we are starting to understand how stochastic and regulatory mechanisms affect the dynamics of the Norwegian Skagerrak cod populations in relation to their local and regional environments. Bjørnstad et al. (1999b) further found that delayed DDM can resonate the recruitment variability, so that long-term trends are induced. Quantifying stochastic and regulatory forces is not only important to understanding how regulation may or may not happen, but also to understanding how long-term fluctuations may, in some cases, arise.

\section{ACKNOWLEDGMENTS}

Thanks are due to the late Rangvald Løversen and to Aadne Sollie for carrying out the sampling resulting in the "Flødevigen data set," as well as a DN-funded project for organizing the data into computer-readable format. Financial support from the MAST program of the European Union (postdoctoral fellowship to JMF at the University of Oslo), from the University of Oslo (through the "Environmental Program" to NCS and JG), and from the National Science Foundation of Norway (postdoctoral fellowship to ONB) made the reported analyses possible.

\section{Literature Cited}

Begon, M., J. L. Harper, and C. R. Townsend. 1996. Ecology. Third edition. Blackwell Science, London, UK.

Bjørnstad, O. N., J.-M. Fromentin, N. C. Stenseth, and J. Gjøsæter. 1999a. A new test for density-dependent survival: the case of coastal cod populations. Ecology 80: $1278-1288$.

Bjørnstad, O. N., J.-M. Fromentin, N. C. Stenseth, and J. Gjøsæter. 1999b. Cycles and trends in cod populations. Proceedings National Academy Sciences U.S. 96:50665071.

Bogstad, B., G. R. Lilly, S. Mehl, O. Palsson, and G. Stefansson. 1994. Cannibalism and year-class strength in Atlantic cod (Gadus morhua) in Arcto-boreal ecosystems (Barents Sea, Iceland and eastern Newfoundland). ICES Journal of Marine Science Symposium 198:576-599.

Bollen, K. A. 1989. Structural equations with latent variables. John Wiley \& Sons, New York, New York, USA.

Borg, A., L. Pihl, and H. Wennhage. 1997. Habitat choice by juvenile cod (Gadus morhua L.) on sandy soft bottoms with different vegetation types. Helgolander Meeresuntersuhungen 51:197-212.

Bromley, P. J., T. Watson, and J. R. G. Hislop. 1997. Diel feeding patterns and the development of food webs in pelagic 0-group cod (Gadus morhua L.), haddock (Melanogrammus aeglefinus L.), whiting (Merlangius merlangus L.), saithe (Pollachius virens L.) and Norway pout (Trisopterus esmarkii Nilsson) in the northern North Sea. ICES Journal of Marine Science 54:846-853.

Caley, M. J., M. H. Carr, M. A. Hixon, T. P. Hughes, G. P. Jones, and B. A. Menge. 1996. Recruitment and the local dynamics of open marine populations. Annual Review Ecology and Systematics 27:477-500.

Carroll, R. J., D. Ruppert, and L. A. Stefanski. 1995. Measurement error in nonlinear models. Chapman \& Hall, London, UK.

Christie, H. 1995. Description of the kelp forest fauna at Froan, Mid Norway; variation in an exposure gradient. NINA Oppdragsmelding 368:1-22. [in Norwegian with English abstract].

Christie, H. 1997. Fauna diversity associated to different macroalgal habitats at the Skagerrak coast of Norway. NINA
Oppdragsmelding 483:1-18. [in Norwegian with English abstract].

Cury, P., and C. Roy. 1989. Optimal environmental window and pelagic fish recruitment success in upwelling areas. Canadian Journal of Fisheries and Aquatic Science 46:670680.

Cushing, D. H. 1990. Plankton production and year class strength in fish populations: an update of the match/mismatch hypothesis. Advances in Marine Biology 26:249293.

Cushing, D. H. 1995. Population production and regulation in the sea: a fisheries perspective. Cambridge University Press, Cambridge, UK.

Dahl, K. 1906. Undersøkelser over nytten av torskeutklæking i Østnorske fjorder. Årsberetning vedkommende Norges fisk. H1:116 pp.

Dalley, E. L., and J. T. Anderson. 1997. Age-dependent distribution of demersal juvenile Atlantic cod (Gadus morhua) in inshore/offshore northeast Newfoundland. Canadian Journal of Fisheries and Aquatic Science 54(Supplement 1):168-176

Danielssen, D. S. 1969. On the migrations of the cod in the Skagerrak shown by tagging experiments in the period 1954-1965. Fiskeridirektoratets skrifter Serie Havundersøkelser 15:331-338.

Danielssen, D. S., and J. Gjøsæter. 1994. Release of 0-group cod (Gadus morhua L.) on the southern coast of Norway in the years 1986-89. Aquaculture and Fisheries Management 25:129-142.

Dannevig, A. 1954. The littoral cod on the Norwegian Skagerrak cost. Rapport et Procès-verbaux des Réunions du Conseil international pour l'Exploration de la mer 136:714

Dickson, R. R., and K. M. Brander. 1993. Effects of a changing windfield on cod stocks of the North Atlantic. Fisheries and Oceanography 2:124-153.

Ellersten, B., P. Fossum, P. Solemdal, and S. Sundby. 1989. Relation between temperature and survival of eggs and firstfeeding larvae of northeast Arctic cod (Gadus morhua L.). Rapport et Procès-verbaux des Réunions du Conseil international pour l'Exploration de la mer 191:209-219.

Fjøsne, K., and J. Gjøsæter. 1996. Dietary composition and the potential of food competition between 0-group cod ( $\mathrm{Ga}$ dus morhua L.) and some other fish species in the littoral zone. ICES Journal of Marine Science 53:757-770.

Folkvord, A., and H. Ottera. 1993. Effects of initial size distribution, day length and feeding frequency on growth, survival and cannibalism in juvenile Atlantic cod (Gadus morhua L.). Aquaculture 114:243-260.

Fromentin, J.-M., J. Gjøsæter, O. N. Bjørnstad, and N. C. Stenseth. 2000. Biological processes and environmental factors regulating the temporal dynamics of the Norwegian Skagerrak cod since 1919. ICES Journal of Marine Science 57:330-338.

Fromentin, J.-M., N. C. Stenseth, J. Gjøsæter, O. N. Bjørnstad, W. Falk, and T. Johannessen. 1997. Spatial patterns of the temporal dynamics of three gadoids species along the Norwegian Skagerrak coast. Marine Ecology Progress Series 155:209-222.

Fromentin, J.-M., N. C. Stenseth, J. Gjøsæter, T. Johannessen, and B. Planque. 1998. Long-term fluctuations in cod and pollack along the Norwegian Skagerrak coast. Marine Ecology Progress Series 162:265-278.

Gjøsæter, J. 1988. Competition for food and predator-prey relationships among young cod (Gadus morhua) and some other fish from shallow waters. Flødevigen Rapportseries 1:1-15.

Gjøsæter, J. 1990. Norwegian coastal Skagerrak cod. Report on the ICES study group of cod stock fluctuations. Appendix III. ICES C.M. G50:155-170. 
Gjøsæter, J., K. Enersen, and S. E. Enersen. 1996. Ressuser av torsk og andre fisk i fjorder på den Norske Skagerrakkysten. Fisken og havet 23:1-28 [in Norwegian].

Gotceitas, V., S. Fraser, and J. A. Brown. 1995. Habitat use by juvenile Atlantic cod (Gadus morhua) in the presence of an actively foraging and non-foraging predator. Marine Biology 123:421-430.

Hassell, M. P., J. Latto, and R. M. May. 1989. Seeing the wood for the trees: detecting density-dependence from existing life-table studies. Journal Animal Ecology 58:883892.

Hayes, D. B., C. P. Ferreri, and W. W. Taylor. 1996. Linking fish habitat to their population dynamics. Canadian Journal Fish and Aquatic Science 53(Supplement 1):383-390.

Hilborn, R., and M. Mangel. 1997. The ecological detective. Princeton University Press, Princeton, New Jersey, USA.

Hixon, M. A., and M. H. Carr. 1997. Synergistic predation, density-dependence, and population regulation in marine fish. Science 277:946-949.

Hjort, J. 1914. Fluctuations in the great fisheries of northern Europe. Viewed in the light of biological research. Rapport et Procès-verbaux des Réunions du Conseil international pour l'Exploration de la mer 20:1-228.

Johannessen, T., and A. Sollie. 1994. Overvåking av gruntvannsfauna på Skagerrakkysten. Fisken og havet 10:91 pp. [in Norwegian, figure legends in English].

Johnson, N. L., S. Kotz, and N. Balakrishnan. 1994. Continuous univariate distribution. Volume 1. John Wiley \& Sons, New York, New York, USA.

Julliard, R., N. C. Stenseth, J. Gjøsæter, K. Lekve, J.-M Fromentin, and D. S. Danielssen. 2001. Natural mortality and fishing mortality in a coastal cod population: a releaserecapture experiment. Ecological Applications, In press.

Keats, D. W., D. H. Steele, and R. South. 1987. The role of fleshy macroalgae in the ecology of juvenile cod (Gadus morhua) in inshore waters off eastern Newfoundland. Canadian Journal of Fisheries and Aquatic Science 65:49-53.

Langfelt, F. 1995. Variasjoner hos Laminaria hyperborea (Gunnerus) Foslie langs kysten av Sør-Norge fra Ytre Oslofjord til Bergen. Thesis. University of Oslo, Norway [in Norwegian].

Lebreton, J.-D. 1989. Statistical methodology for the study of animal populations. Bulletin de l'Institut International de Statistique 53:267-282.

Levin, P. S. 1994. Fine-scale temporal variation in recruitment of a temperate demersal fish. The importance of settlement versus postsettlement loss. Oecologia 97:124-133.

Levin, P. S., R. Petrik, and J. Malone. 1997. Interactive effects of habitat selection, food supply and predation on recruitment of an estuarine fish. Oecologia 112:55-63.

May, R. C. 1974. Larval mortality in marine fishes and the critical period concept. Pages 3-19 in J. H. S. Blaxter, editor. The early life history of fish. Springler-Verlag. New York, New York, USA.

McCullagh, P., and J. A. Nelder. 1989. Generalized linear models. Second edition. Chapman \& Hall, London, UK.

Mertz, G., and R. A. Myers. 1995. Estimating the predictability of recruitment. Fisheries Bulletin 93:657-665.

Moy, F. E., S. Fredriksen, J. Gjøsæter, S. Hjolman, T. Jacobsen, T. Johannesen, T. E. Lein, E. Oug, and Ø. F. Tvedten.
1997. Utredning om benthossamfunn på kyststrekningen Fulehuk-Stad. NIVA rapport LNR 3551-96:0-84. [in Norwegian].

Myers, R. A. 1998. When do environment-recruit correlations work? Reviews in Fish Biology and Fisheries 8:285305.

Myers, R. A., and N. G. Cadigan. 1993a. Density-dependent juvenile mortality in marine demersal fish. Canadian Journal of Fisheries and Aquatic Science 50:1576-1590.

Myers, R. A., and N. G. Cadigan. 1993b. Is juvenile natural mortality in marine demersal fish variable? Canadian Journal of Fisheries and Aquatic Science 50:1591-1598.

Myers, R. A., and N. G. Cadigan. 1995. Was an increase in natural mortality responsible for the collapse of northern cod? Canadian Journal of Fisheries and Aquatic Science 52: $1274-1285$.

Noreide, J. T., and J. H. Fosså. 1992. Diet overlap between two subsequent year-classes of juvenile cod (Gadus morhua L.) and wild and reared cod. Sarsia 77:111-117.

Ottersen, G., and S. Sundby. 1995. Effects of temperature, wind and spawning stock biomass on recruitment of ArctoNorwegian cod. Fisheries Oceanography 4:278-292.

Pedersen, A., N. W. Green, F. Moy, and M. Walday. 1994. Langtidsovervåking av miljøkvaliteten i kystområdene av Norge. Datarapport 1993. Hardbunnsunders $\varnothing$ kelser. NIVA rapport 554/94:0-86 [in Norwegian].

Pepin, P., and T. H. Shears. 1995. Influence of body size and alternate prey abundance on the risk of predation to fish larvae. Marine Ecology Progress Series 128:279-285.

Pimm, S. L. 1991. The balance of nature. University Chicago Press. Chicago, Illinois, USA.

SAS 1996. SAS statistical software. Version 6.11. SAS Institute, Cary, North Carolina, USA.

Skreslet, S. 1989. Spatial match and mismatch between larvae of cod (Gadus morhua L.) and their principal prey, nauplii of Calanus finmarchicus (Gunnerus). Rapport et Procès-verbaux des Réunions du Conseil international pour l'Exploration de la mer 191:258-263.

Sokal, R. R., and F. J. Rohlf. 1995. Biometry. Third edition. W.H. Freeman \& Co., New York, New York, USA.

Stenseth, N. C., O. N. Bjørnstad, W. Falck, J.-M. Fromentin, J. Gjøsæter, and J. Gray. 1999. Dynamics of coastal cod populations: intra- and inter-density-dependence and stochastic processes. Proceedings of the Royal Society London, Series B 266:1645-1654.

Sundby, S. 1995. Wind climate and foraging of larval and juvenile Arcto-Norwegian cod (Gadus morhua). Pages 405-415 in R. J. Beamish, editor. Climate change and northern fish populations. Canadian Special Publication of Fisheries and Aquatic Science 121.

Tupper, M., and R. G. Boutilier. 1995a. Effects of habitat on settlement, growth, and postsettlement survival of Atlantic cod (Gadus morhua). Canadian Journal of Fisheries and Aquatic Science 52:1834-1841.

Tupper, M., and R. G. Boutilier. 1995b. Size and priority at settlement determine growth and competitive success of newly settled Atlantic cod. Marine Ecology Progress Series 118:295-300.

Williams, D. W., and A. M. Liebhold. 1995. Detection of delayed density-dependence: effects of autocorrelation in an exogenous factor. Ecology 76:1005-1008. 